Rhode Island College

Digital Commons @ RIC

$5-1-2013$

\title{
An Exploration of the Barriers in the Prevention and Control of High Blood Pressure Among West African Immigrants in Rhode Island
}

Ntaobasi Patrick Udeh

Rhode Island College

Follow this and additional works at: https://digitalcommons.ric.edu/etd

Part of the Nursing Commons

\section{Recommended Citation}

Udeh, Ntaobasi Patrick, "An Exploration of the Barriers in the Prevention and Control of High Blood Pressure Among West African Immigrants in Rhode Island" (2013). Master's Theses, Dissertations, Graduate Research and Major Papers Overview. 225.

https://digitalcommons.ric.edu/etd/225

This Major Paper is brought to you for free and open access by the Master's Theses, Dissertations, Graduate Research and Major Papers at Digital Commons @ RIC. It has been accepted for inclusion in Master's Theses, Dissertations, Graduate Research and Major Papers Overview by an authorized administrator of Digital Commons @ RIC. For more information, please contact digitalcommons@ric.edu. 
Running head: HIGH BLOOD PRESSURE IN WEST AFRICAN IMMIGRANTS IN RI

\section{AN EXPLORATION OF THE BARRIERS IN THE PREVENTION AND CONTROL OF HIGH BLOOD PRESSURE AMONG WEST AFRICAN IMMIGRANTS IN RHODE ISLAND}

by

Ntaobasi Patrick Udeh

A Major Paper Submitted in Partial Fulfillment

Of the Requirements for the Degree of

Master of Science in Nursing

In

The School of Nursing

Rhode Island College

2013 


\title{
HIGH BLOOD PRESSURE IN WEST AFRICAN IMMIGRANTS IN RI
}

\begin{abstract}
This is a report of a pilot study to explore the barriers to the prevention and control of high blood pressure by West African immigrants in Rhode Island. The incidence of high blood pressure is high in African Americans with many possible contributory factors documented. However, little is known about possible barriers to the control of high blood pressure among specific black ethnic populations such as West African immigrants living in Rhode Island. A qualitative research design employing a semi-structured interview was utilize to explore the issue. The barriers to high blood pressure management reported by these West Africans immigrants reported included: psychosocial stressors, inability to adopt lifestyle changes such as diet and exercise, belief system, and a lack of complete adherence to medication regimen. The study also highlighted the fact that some primary care providers for these patients are not following the recommended interventions for the management of high blood pressure in people of black ancestry. The findings of this pilot study support the need for provider use of available treatment guidelines for population from black ancestry and the necessity for adequate patient education in the areas of stress management strategies and lifestyle modification as adjuncts to medication prescribed for high blood pressure management.
\end{abstract}




\section{HIGH BLOOD PRESSURE IN WEST AFRICAN IMMIGRANTS IN RI}

\section{Acknowledgements}

It is you O Lord that has done this great and mighty work in my life, thank you for your strength and grace that carried me through it all and for this I give you praise. It is impossible to acknowledge all the people who have assisted me in this journey personally, spiritually, financially, and academically. However, I will begin by saying thank you to all the MSN faculty members in Rhode Island College School of nursing, especially Professor Peggy Matteson for her effort in making this project become a reality. Her devotion to guide me through this project and personal words of encouragement gave me the courage to keep going on to the end. Thank you Professors Cindy Padula, Margaret Mock, and Nancy Blasdell ;when no one really believed I could make it through the program due to my limited nursing experience, you three believed otherwise, and that simply gesture strengthened my belief in myself and pushed me on to complete this journey.

I am really grateful to Dr Kwame Afriye-Dapa, and Mr Julius Kolawale, for the great work you do in our community and your support through this project. May God bless you and strengthen your hands to continue. Through this journey, I met the best nursing preceptors in Rhode Island- Jane Frietas, Carol Pearson Riel, Liza Murphy, and Alice Haynes, thank you all for all your hard work in making this dream a reality.

To my husband words are not enough to express my gratitude to you. Thanks for giving me a chance to pursue my dream, thanks for being there to hold me through it all, thanks for the financial drain I put you through, thanks for listening to my screams and complains, thanks for every little thing that I cannot simply list here. To my lovely 


\section{HIGH BLOOD PRESSURE IN WEST AFRICAN IMMIGRANTS IN RI}

children, my six little angels, you indeed are my inspiration. Thank you for having patience with me and showing understanding when I couldn't enroll you in those sporting activities that you love. Thanks for sharing me with my books. I could never have made it through without your little smiles, words, and love. I love you all so dearly, now you have your Mom back.

Finally, I want to say thank you to all my family and friends especially my Mom and Dad whose prayers, encouragement and help saw me through. Mom, you sometimes hid your pain from me, to prevent me from being worried; you stayed strong even when it seemed impossible for you to be strong. You are such a strong woman and I love you dearly. Thanks to all my pastors for all your prayers, words of encouragement and support through this journey. May our God richly bless you all in Jesus name, Amen. I cannot but say thank you so much to Mrs. OluFunke Olubowale for all her support through it all and to my best friend Koko Ukpong Ika, you left me on the day I finished this journey. You did not wait to celebrate with me; I know you did not plan it this way, only God knows why He decided to take you to be with Him at this time. Rest in Peace my sister and my friend, till we meet at His feet in glory. I will conclude by saying once again, to God be the glory for the great things He has done. 


\section{CONTENTS}

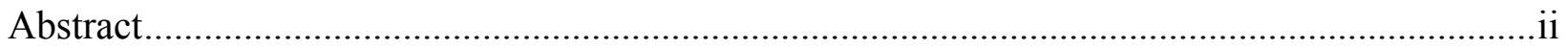

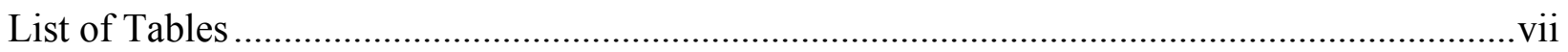

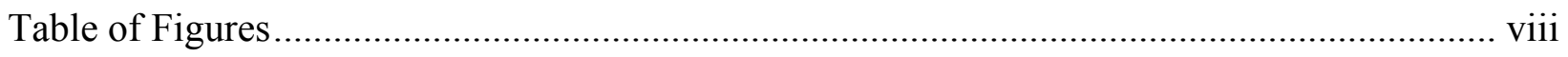

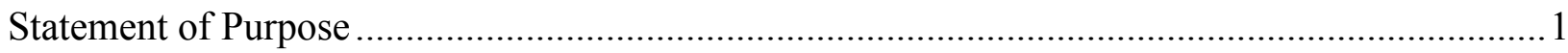

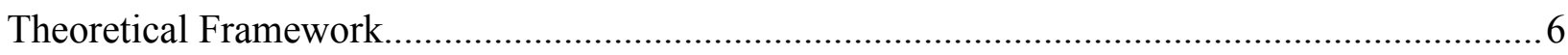

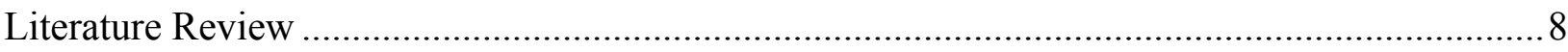

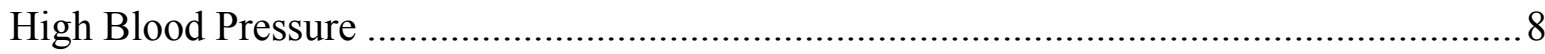

Epidemiology of High Blood Pressure ................................................................ 10

Treatment of High Blood Pressure in the General Population......................................... 12

Treatment of High Blood Pressure in People of Black Ancestry..................................... 14

Barriers to Blood Pressure Control in the General Population ........................................ 17

Barriers to Blood Pressure Control in West Africans in Africa.......................................... 18

Barriers to Blood Pressure Control in Blacks/African Americans..................................... 21

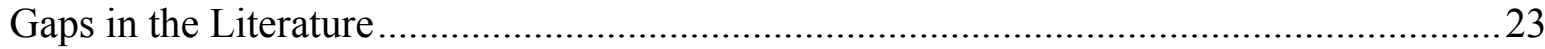

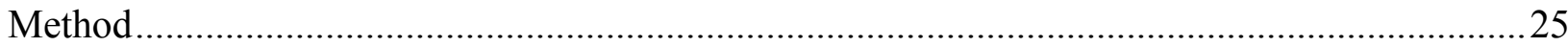

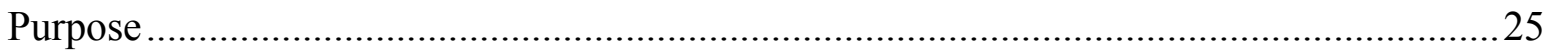

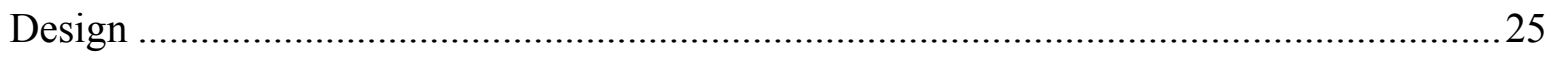

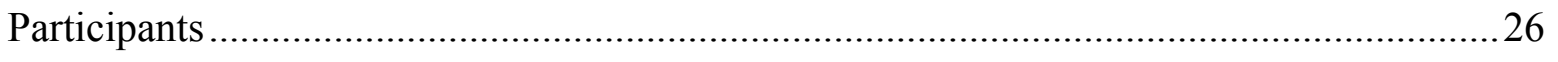

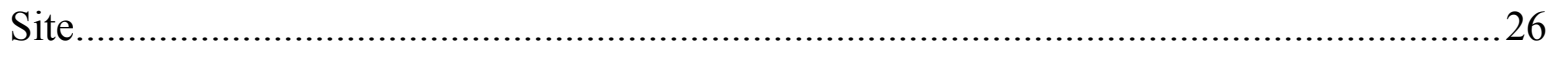

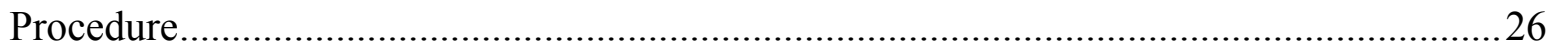

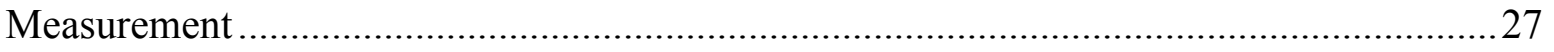

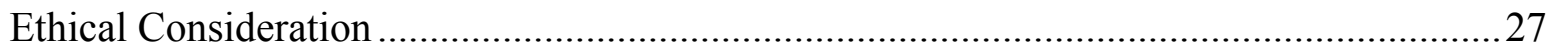




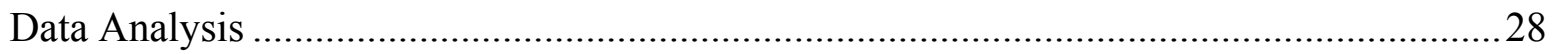

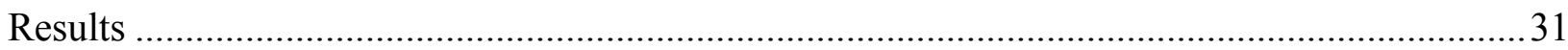

Conclusion and Implication for Advanced Nursing Practice ........................................................ 35

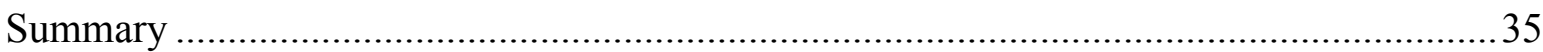

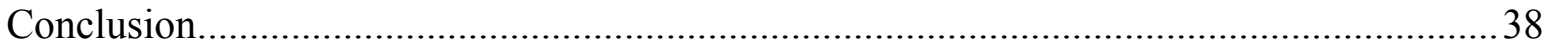

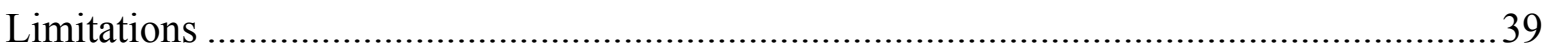

Recommendations and Implications for Advance Practice Nursing (APRN) .......................39

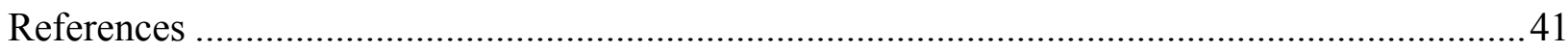

Appendix A Dietary Approach to Stop Hypertension..................................................................5

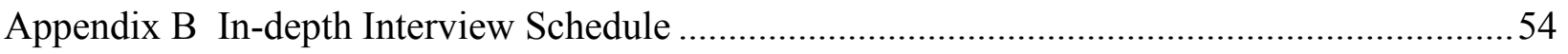

Appendix C Demographic Data Questions ..............................................................................5

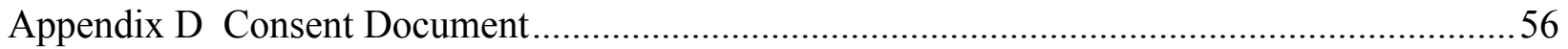


HIGH BLOOD PRESSURE IN WEST AFRICAN IMMIGRANTS IN RI

\author{
List of Tables
}

Table 1 Stages of Hypertension ............................................ 9

Table 2 Hypertension Subclass.............................................. 10

Table 3 Demographic characteristics of study participants .........................32

Table 4 Barriers to high blood pressure control...................................33 


\section{HIGH BLOOD PRESSURE IN WEST AFRICAN IMMIGRANTS IN RI}

\section{Table of Figures}

Figure 1. Algorithm for the treatment of Hypertension. ......................................................... 14

Figure 2. Algorithm for Treatment of Hypertension in Blacks..................................................... 16

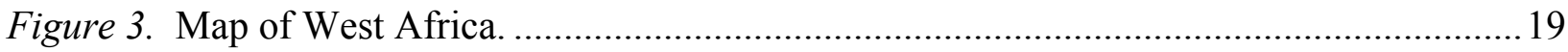




\section{HIGH BLOOD PRESSURE IN WEST AFRICAN IMMIGRANTS IN RI}

\section{Statement of Purpose}

The National Health and Nutrition Examination Survey (NHANES) reports that approximately one third of United State (U.S) adults' have a diagnosis of high blood pressure (Center for Diseases Control [CDC], 2012). This is the equivalent of roughly 66.9 million Americans, of whom an estimated 35.8 million have uncontrolled hypertension (CDC, 2012). Hypertension is found to occur disproportionately: $43 \%$ of non-Hispanic black men and $45.7 \%$ of non-Hispanic black women are estimated to be living with high blood pressure, as compared to $33.9 \%$ of non-Hispanic white man and $31.3 \%$ of non-Hispanic white women. Rahman, Douglas, \& Wright, (1997) noted that in the U.S. the population of blacks have the highest morbidity and mortality from hypertension in the U.S and it ranks among the highest in the world. Of more than 2.4 million deaths in the U.S in $2008 ; 347,689$ were either caused by or attributed to high blood pressure and 13,372 of those were non-Hispanic blacks (Roger et al., 2012). In 2010, the projected financial burden of high blood pressure in health care services, cost of medications, and missed days of work was 131 billion dollars (CDC, 2012).

High blood pressure places a person at major risk for cardiovascular diseases, kidney disease, and cerebrovascular accidents (McCance, Brashers, \& Rote, 2010). It is often called "the silent killer" as the signs and symptoms go unnoticed until major damage has been done (CDC, 2011). Data obtained from the Rhode Island Heart Diseases and Stroke Prevention Plan showed that in 2008, 4.0\% of Rhode Island (RI) adults had suffered a myocardial infarction, similar to the US national average of $4.2 \%$. In addition, when comparing people with coronary artery diseases (a sum of those with 
atherosclerosis without a myocardial infarction and those who have had a myocardial infarction), $4.6 \%$ had this diagnosis compared to the national rate of $4.2 \%$; and $2.3 \%$ of Rhode Islanders had experienced a stroke, as compared to $2.6 \%$ for stroke nationally (Pearlman, Affleck, Everage, \& Goldman, 2009).

Although specifics regarding the racial prevalence of cardiovascular disease, and stroke were not reported, Pearlman et al., (2009) noted that the age-adjusted hospitalization from heart disease and stroke was higher among non-Hispanic blacks than those of non-Hispanic Whites or Hispanic descent. RI has approximately 52, 800 African Americans (Kaiser Family Foundation [KFF], 2010), with about 12.5\% directly from Africa. Of those immigrants, West Africans make up the highest population (Migration Policy Institute, 2011). The comparison data related to non-Hispanic blacks' living in the U.S. implies that the diagnosis and treatment of hypertension within members of the West African immigrant community must be investigated so that culturally appropriate services may be developed.

International studies have pointed to the fact that there is an increase in hypertensive diseases in urbanized sub-Saharan Africans. This increase has been attributed to multi-factorial causes, ranging from socioeconomic stress, lack of access to healthcare, poor diet or dietary excess, obesity, alcohol consumption, lack of exercise, and cultural beliefs (Opie \& Seedat, 2005). Studies of urbanized sub-Saharan Africans may have a correlation to the epidemic of hypertension in the U.S. among African Americans. However, no significant studies have been found that determine the prevalence of hypertension in West African immigrants living in the U.S. 
The lack of literature related specifically to West African immigrants might be attributed to the fact that all "blacks" or people of African origin tend to be clustered by researchers into one demographic category - "Black non-Hispanic".

The problem with this generalization is that the population of African immigrants represents a wide variety of cultural and ethnic groups all with lifestyles that differ from African Americans who have lived as part of the U.S culture for one or more generations. These cultural differences among the immigrants undoubtedly impact the health of the members of various aggregates in different ways.

There have been several studies conducted with different minority groups that support the inference that immigrants may experience barriers when seeking culturally appropriate health promotion and illness interventions to control their hypertension. For example, a study of the occurrence of high blood pressure among a group of predominantly first generation Korean-American elderly, discovered that the prevalence of hypertension was very high (99\%) among this population. About $66 \%$ of those individuals identified were not receiving care for high blood pressure (Kang, Han, Kim, \& Kim, 2006). This group of Korean American elders reported issues such as inability to access the healthcare system, lack of insurance, and lack of Korean doctors who understood their belief system as barriers (Kang et al., 2006).

Similarly, a focus group conducted in RI among African immigrants suggested that there exist unique factors among African immigrants in RI that generally impact their ability to obtain appropriate healthcare. The focus group participants highlighted the fact that in Africa, discussions concerning one's health are not done openly and as such, 
African immigrants in RI, tend to not be "open" about their healthcare needs; and were less likely to seek medical help. In addition, participants reported facing discrimination within the healthcare system because they lacked health insurance. Members of the focus group reported that it is not a practice of their culture to visit the doctor regularly for “check-ups". Participants further stated that, they often ignore symptoms pertaining to their health until they become so ill and unable to function (African Alliance of Rhode Island, 2011).

This research study, An Exploration of the Barriers in the Prevention and Control of High Blood Pressure Among West African Immigrants in Rhode Island has been developed based on the premise that multiple barriers hinder effective prevention and treatment of high blood pressure among people of African ancestry domestically and internationally. Based on studies of African Americans in the U.S and Africans in subSaharan Africa these barriers are multifaceted. However, specific barriers and their strength of influence vary from sub-group to sub-group. The Institute of Medicine (IOM) recommended that population-based strategies that are able to reach a large number of people and improve their wellbeing should be given priority in the management of hypertension (Institute of Medicine, 2010). This recommendation by the IOM is supported by the explanatory model of diseases as proposed by Kleinman (1980) that suggests that patients and providers have different ways of explaining sickness and treatment, including explanations for the etiology, timing, onset of symptoms, pathophysiological processes involved, the natural course and level of severity, and appropriate corresponding treatments. Understanding the patient's perspective when 
working with each of them regarding their treatment plan for hypertension is the key to improving the outcome of successful adherence. Hence, the aim of this research was to explore the barriers experienced by five West African immigrants living in Rhode Island when they sought care in response to a diagnosis of high blood pressure. 


\section{HIGH BLOOD PRESSURE IN WEST AFRICAN IMMIGRANTS IN RI}

\section{Theoretical Framework}

The theoretical framework that guided this study was Madeline Leininger's Cultural Care Theory of Diversity and Universality. Leininger (2002), promotes a model of nursing care that is based on understanding the holistic and comprehensive culture of care as applicable with in Western and non-Western cultures (Alligood \& Tomey, 2010). According to Leininger (2002), each person develops their world-view based on a variety of factors such as social structure, language, generic and professional care, ethno-history, and the environment. The theory pre-supposes that "care diversities and universalities existed among and between cultures in the world" (p190).

The basic purpose of Leininger's cultural care theory is to provide a framework to uncover both the similarities and differences among and between individuals and groups, concerning culturally based care factors that influence their health, wellbeing, illness, or death (Leininger, 2002). By doing this, Leininger believes that the information obtained can be used to provide culturally congruent, safe, and meaningful care to patients. In establishing this theory, Leininger (2002) made a few assumptions:

Care is the essence of nursing and a distinct, dominant, central, and unifying focus; (2) Culturally based care is essential for wellbeing, health, growth, survival, and in facing handicap, or death; (3) Culturally based care is the most comprehensive, holistic, and particularistic means to know, explain, interpret, and predict beneficial congruent

care practices; (4) Culturally based care is essential to 
curing; (5) Culture care concepts, meanings, expressions, patterns, processes, and structural forms vary transculturally, with diversities (differences) and some universalities (commonalities).These assumptions are guided by four main tenets: (1) diversity and universality exist in the process of caring; (2) an individual or group's worldview, culture, and social structures do have a great impact on the outcome of care; (3) indigenous (emic) practices and professional (etic) practices influence care services; and (4) there are three major action and decision guides in giving culturally safe and congruent care, namely: culture care preservation or maintenance, culture care accommodation or negotiation, and culture care repatterning or restructuring. ( $\mathrm{p} 192)$

West Africans as a whole are a multiethnic group with intricate cultural and religious beliefs and practices. These beliefs and practices contribute to their worldview of health and sickness. It is essential that healthcare providers try to provide appropriate interventions for patients with hypertension and understand both the concerns of the individual and the beliefs and expectations of the culture of their community. 


\section{HIGH BLOOD PRESSURE IN WEST AFRICAN IMMIGRANTS IN RI}

\section{Literature Review}

A review of the existing relevant literature was conducted to discover the reported barriers in high blood pressure management experienced by West African immigrants. The electronic databases CINAHL, MEDLINE, UP TODATE, MD'S CONSULT, OVID, and PUBMED were searched using the key words: hypertension in blacks, high blood pressure and West African immigrants, high blood pressure and West Africa; hypertension and minorities; hypertension control; barriers to treatment of high blood pressure; as well as high blood pressure and culture. Titles and abstracts were reviewed to identify possible articles and then full text versions were read to determine relevance of the paper to the focus of this research. The search for articles was limited to English language publications. No limits were set on date of publication. A review of selected key literature is presented below.

\section{High Blood Pressure}

High blood pressure is defined as "a progressive cardiovascular syndrome arising from complex and integrated etiologies" (Giles, Materson, Cohn, \& Kostis, 2009, p611). Table 1 outlines how the Joint National Committee on Prevention, Detection, Evaluation, and Treatment of High Blood Pressure VII (JNC7) standardized the definition of hypertension. 
Table 1

Stages of Hypertension

\begin{tabular}{|l|l|l|}
\hline $\begin{array}{l}\text { Stages of Blood } \\
\text { Pressure }\end{array}$ & Systolic Value (mm Hg) & Diastolic (mm Hg) \\
\hline Normal & Less than 120 & Less than 80 \\
\hline Prehypertension & $120-139$ & $80-90$ \\
\hline Stage 1 Hypertension & $140-159$ & $90-99$ \\
\hline Stage 11 hypertension & $\begin{array}{l}\text { Greater than or equal to } \\
160\end{array}$ & Greater than or equal to 100 \\
\hline
\end{tabular}

(Chobanian et al, 2004, p.11)

The JNC7 classification (Chobanian et al. , 2004) identified that the following

parameters must be met, for accurate classification to occur:

(1) The reading must be an average of two blood pressure measurements taken at two or more health care provider office visits.

(2) The patient should be seated quietly in a chair for at least five minutes, with feet touching the floor and arm supported at heart level.

(3) The equipment used for measurement must be well maintained and properly calibrated.

(4) The bladder cuff used must be of appropriate size and should encircle $80 \%$ of the arm.

(5) Caffeine and smoking should be avoided at least thirty minutes prior to blood pressure measurement as this can falsely elevate the blood pressure.

The JNC7 classification has received the support of the American Heart Association [AHA] (Pickering et al, 2005). Further specificity was achieved in labeling when the AHA added three more subclasses: 
Table 2

Hypertension Subclasses

\begin{tabular}{|l|l|l|}
\hline Subclass & Systolic Value $(\mathrm{mmHg})$ & Diastolic (mm Hg) \\
\hline $\begin{array}{l}\text { Isolated Systolic } \\
\text { Hypertension }\end{array}$ & Greater than or equal to 140 & Less than or equal to 90 \\
\hline $\begin{array}{l}\text { Isolated Diastolic } \\
\text { Hypertension }\end{array}$ & Less than or equal to 140 & Greater than or equal to 90 \\
\hline $\begin{array}{l}\text { White-Coat hypertension or } \\
\text { Hypolated Office }\end{array}$ & $\begin{array}{l}\text { Persistently elevated } \\
\text { average office systolic } \\
\text { blood pressure of greater } \\
\text { than 140, and ambulatory } \\
\text { systolic reading of less than } \\
135\end{array}$ & $\begin{array}{l}\text { Persistently elevated } \\
\text { diastolic blood pressure of } \\
85\end{array}$ \\
\hline
\end{tabular}

(Pickering et al, 2005)

The U.S Preventative Services Task Force (USPSTF), responsible for making evidenced-based recommendations about clinical preventive services such as: screenings, counseling services, or preventive medications; has tagged the JNC7 recommendations as a "Grade A" recommendation (The U.S Preventative Services Task Force [USPSTF], 2007). It is expected that the JNC7 will be reviewed and possibly revised to JNC8 by the end of 2013.

As definitive as the numbers make the definitions, some clinicians have argued that assigning numerical boundaries to the levels of hypertensive disease is an arbitrary measure not totally predictive of a patient's risk. Therefore, all clinicians are encouraged to consider both the relative and absolute risk of an individual patient, when considering the development of a diagnosis and treatment plan (Kaplan, 1983).

\section{Epidemiology of High Blood Pressure}

High blood pressure affects one in three adults worldwide and is noted to be the leading behavioral and physiological risk factor for individuals. Globally, approximately 
$51 \%$ of all deaths from stroke, and $45 \%$ of deaths coronary heart disease are attributable to high blood pressure (World Health Organization [WHO], 2012). In the U.S. approximately 66.9 million adults ages 18 and above have high blood pressure (CDC, 2012). The prevalence of high blood pressure is almost equally distributed between men and women, with $80 \%$ of hypertensive adults being aware of their disease condition. Seventy one percent of those who are aware of their hypertensive status are using antihypertensive medications, but only $48 \%$ have managed to get their hypertension under control (Roger et al, 2012).

The prevalence of hypertension among U.S. blacks is the highest in the world (Roger et al, 2012). In comparison to people of other races, U.S. blacks develop high blood pressure at a younger age, and have much higher average blood pressures. As a result, the U.S. black population has a " 1.3 times greater rates of nonfatal stroke, 1.8 times greater rate of fatal strokes, 1.5 times greater rates of attributable cardiovascular deaths. U.S blacks have also been found to have 4.2 times greater rate of end-stage kidney disease" than the general population (Roger et al., p. 89).

A probability sample of non-institutionalized English or Spanish-speaking adults in Dallas County was studied by Drazner et al., (2005) to determine the presence of left ventricular hypertrophy ( $\mathrm{LVH})$, a common cardiac dysfunction related to prolonged hypertensive state in the general population. The study sampled 1335 black and 858 whites. The results of the study showed that in comparison to whites, blacks had a higher left ventricular mass and a 2-3 fold higher prevalence of LVH than the general population. The prevalence of LVH was more pronounced in the subgroup of blacks 
with hypertension. The study concluded that the occurrence of LVH in this group is probably the cause of most cardiovascular related deaths in this subgroup. Roger et al. (2012) noted that the rate of hypertension varies substantially within the black community. Higher rates were more likely to occur among middle-aged or older adults who were overweight or obese, less educated, physically inactive, or blacks with comorbidities such as diabetes mellitus. On the other hand, lower rates were more likely to be found among younger blacks even those who were overweight or obese. In addition, Roger et al. (2012) found that uncontrolled hypertension was seen more frequently in males and people with less contact with physicians.

The prevalence of hypertension in the continent of Africa has been found to be higher in populations living in urbanized regions than the rural areas. Separate regional studies conducted in Nigeria, Gambia, and Ghana showed the prevalence of hypertension to be higher in urban dwellers that were described as being more educated and prosperous subset of the society. These urban dwellers were also noted to be more obese compared to their rural counterparts (Kaufman, Owoaje, James, Rotimi, \& Cooper, 1996; and Agyemang 2006). As with the U.S. blacks, hypertension was found to occur more in African women than men (Agyemang, 2006).

\section{Treatment of High Blood Pressure in the General Population}

The goal of treatment of high blood pressure, as recommended by JNC 7 is to reduce cardiovascular and renal morbidity and rates of patient mortality (Chobanian et al., 2004). To achieve this, a combination of lifestyle modification and pharmacological 
intervention with antihypertensive medication has been recommended as shown in the algorithm (Figure 1) below.

The recommended lifestyle modifications include: weight reduction to maintain a body mass index of $18.5-24.9 \mathrm{~kg} / \mathrm{m} 3$; adoption of a diet rich in fruits, vegetables, low-fat dairy products, and reduced content of saturated and total fat, known as the Dietary Approach to Stop Hypertension (DASH diet as seen in Appendix 1); engaging in a 30 minutes per day of vigorous physical activity, such as brisk walking, and aerobics; reduction of dietary sodium to not more than $100 \mathrm{mmol}$ per day (about 1 teaspoon of table salt per day); and limiting alcohol consumption to no more than two drinks per day for men (e.g. $24 \mathrm{oz}$. Beer, or $10 \mathrm{oz}$. Wine), and one drink (e.g. $12 \mathrm{oz}$ of beer, or $5 \mathrm{oz}$ of wine) for women (Chobanian et al., 2004). 


\section{JNC 7: algorithm for treatment of hypertension}

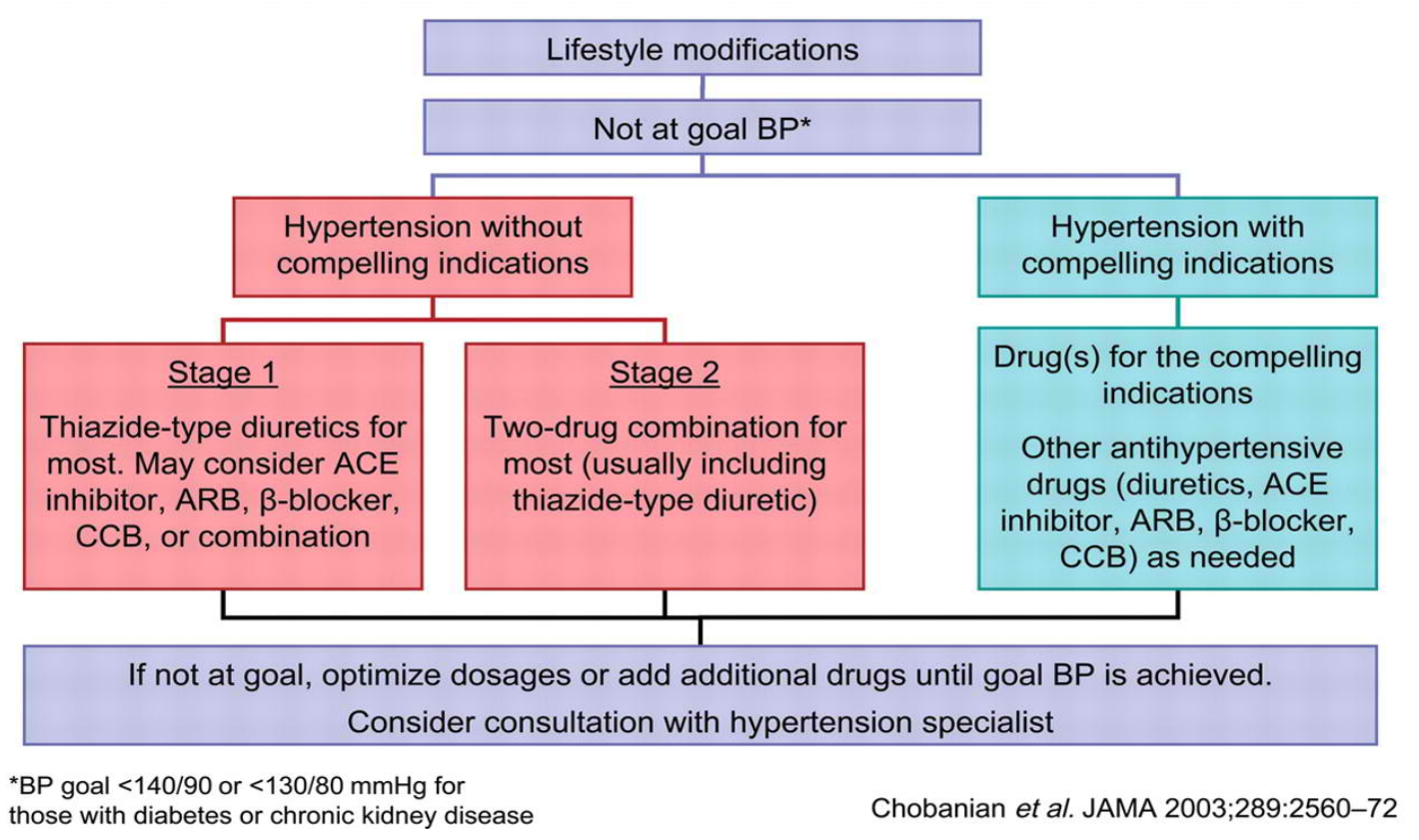

Figure 1. Algorithm for the treatment of Hypertension.

\section{Treatment of High Blood Pressure in People of Black Ancestry}

The physiological mechanism of high blood pressure in blacks has been associated with low renin levels and high salt sensitivity (Kaplan, 1998). As a result, when mono-therapy is needed for the treatment of hypertension in blacks, thiazide diuretic and calcium channel blockers are the recommended choices (Flack et al, 2010). This is based on data that suggest that the low renin levels found in blacks reduces the 
therapeutic efficacy of angiotensin enzyme inhibitors (ACEI) and aldosterone receptor blocking agents (ARB). This association has been confirmed by randomized control trials most notably the ALLHAT (Anti-hypertensive and Lipid-Lowering Treatment to Prevent Heart Attack) trial and the SOLVD (Studies on Left Ventricular Dysfunction) trial (Wright et al., 2005; Exner, Dries, Domanski, \& Cohn, 2001). A consensus statement by the International Society on Hypertension in Blacks (ISHIB) recommends that: (1) it is necessary to initiate two antihypertensive medications if the blood pressure is greater than $15 / 10 \mathrm{mmHg}$ above targeted goal; (2) renin-angiotensin system (RAS) blockers such as ACE inhibitors or Angiotensin Receptor Blockers (ARBs) in conjunction with a thiazide diuretic or calcium channel blocker should be initiated in patients with kidney disease and/or diabetes mellitus; and (3) a beta blocker should be added to thiazide diuretic/calcium channel blocker in cases of heart failure. It is further recommended that a BP target of less than $130 / 80 \mathrm{mmHg}$ be established if comorbid conditions like diabetes mellitus, chronic kidney disease, and metabolic syndrome, known vascular diseases and/or heart disease exist (Flack et al., 2010). The algorithm for treatment of hypertension in black is presented in Figure 2 


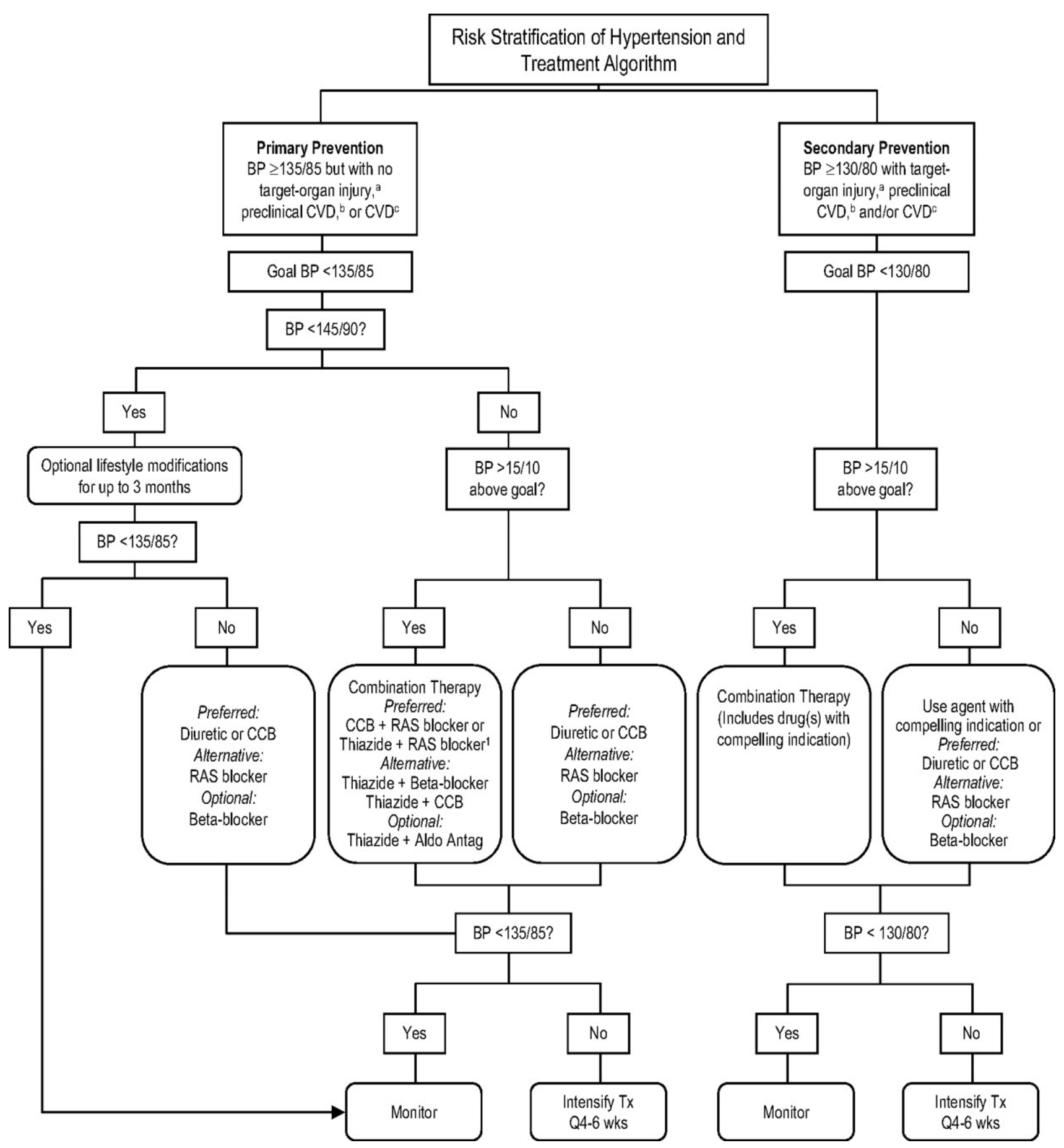

Figure 2. Algorithm for Treatment of Hypertension in Blacks. (Flack et al, 2010). 


\section{Barriers to Blood Pressure Control in the General Population}

Achieving optimal blood pressure levels among the general population of people with hypertension has been a challenge for providers worldwide, despite numerous guidelines, research, and clinical trials (Wang, Alexander, \& Stafford, 2007). The NHANES report showed that about 31.1 million (46.5\%) U.S adults with hypertension have their blood pressure controlled. On the other hand, 35.8 million, accounting for $53.5 \%$, have uncontrolled hypertension. Of those with uncontrolled hypertension, 14.1million are unaware of their disease, 5.7 million are aware but untreated, and 16.0 million are aware and treated (CDC, 2012).

Three major types of barriers have been identified as contributing to inadequate blood pressure control in the general U.S. These barriers are related to the patient, the physician, and the system (Cook et al, 2006; Ogedegbe, 2008). The patient characteristics include lack of adherence to treatment regimen and referrals, asymptomatic nature of hypertension, linguistic and cultural beliefs, psychosocial challenges, patient's acceptance of disease, difficulty making lifestyle modifications, low health literacy, comorbid conditions and a lack of social supports (Cook et al., 2006; Ogedegbe, 2008). Ogedegbe (2008) noted that the level of adherence by hypertensive patients with prescribed medication therapies ranged from $43 \%$ to $88 \%$. He attributed the poor adherence to patient's beliefs about their illness, fear of complications, and the side effects of prescribed medications. 
The barriers to high blood pressure control at the provider level, includes lack of specificity when developing a plan of drug therapy. Many clinicians do not titrate blood pressure medications to the appropriate levels required to maintain optimum blood pressure control (Havranek, 2008). The presence of a communication barrier between clinicians and patients has also been shown to impede effective blood pressure control. Clinicians who are unable to communicate in a language and manner that their patients understand cannot effectively validate that the treatment plan they are offering to their patients can be followed appropriately. It has been noted that many clinicians are either unaware of treatment guidelines for the aggregate population they serve, or are aware, but choose to not follow the recommended guidelines (Oliveria, Lapuerta, McCarthy, L'Italien, Berlowitz, \& Asch, 2002).

At the system level, identified barriers to high blood pressure control include a treatment regimen which is not multidisciplinary based, a lack of resources for educating patients at the appropriate educational level, and difficulty coordinating patients care (Cook et al., 2006; Ogedegbe, 2008). It is important to note that access to care itself has not been identified as a barrier to blood pressure control. And it is important to note that the NHANES report showed that patients who were able to access the healthcare system did not show better blood pressure control than those who were unable to access treatment (CDC, 2012).

\section{Barriers to Blood Pressure Control in West Africans in Africa}

West Africa is the western region of the continent of Africa. It is composed of 16 countries namely Benin, Burkina Faso, Cote d Ivoire (Ivory Coast), Gambia, Ghana, 
Guinea, Guinea Bissau, Liberia, Mali, Mauritania, Niger, Nigeria, Senegal, Sierra Leone and Togo and the Islands of Cape Verde (United Nations Statistics Division [UN Stats], 2012) The geographical location of the area known as West Africa is highlighted in green on the map of Africa below (Fig 2). The people of West Africa are multicultural and multiethnic, however there exists cultural similarities across the region that are uniquely different from other parts of the African Continent (Atlas, n.d).

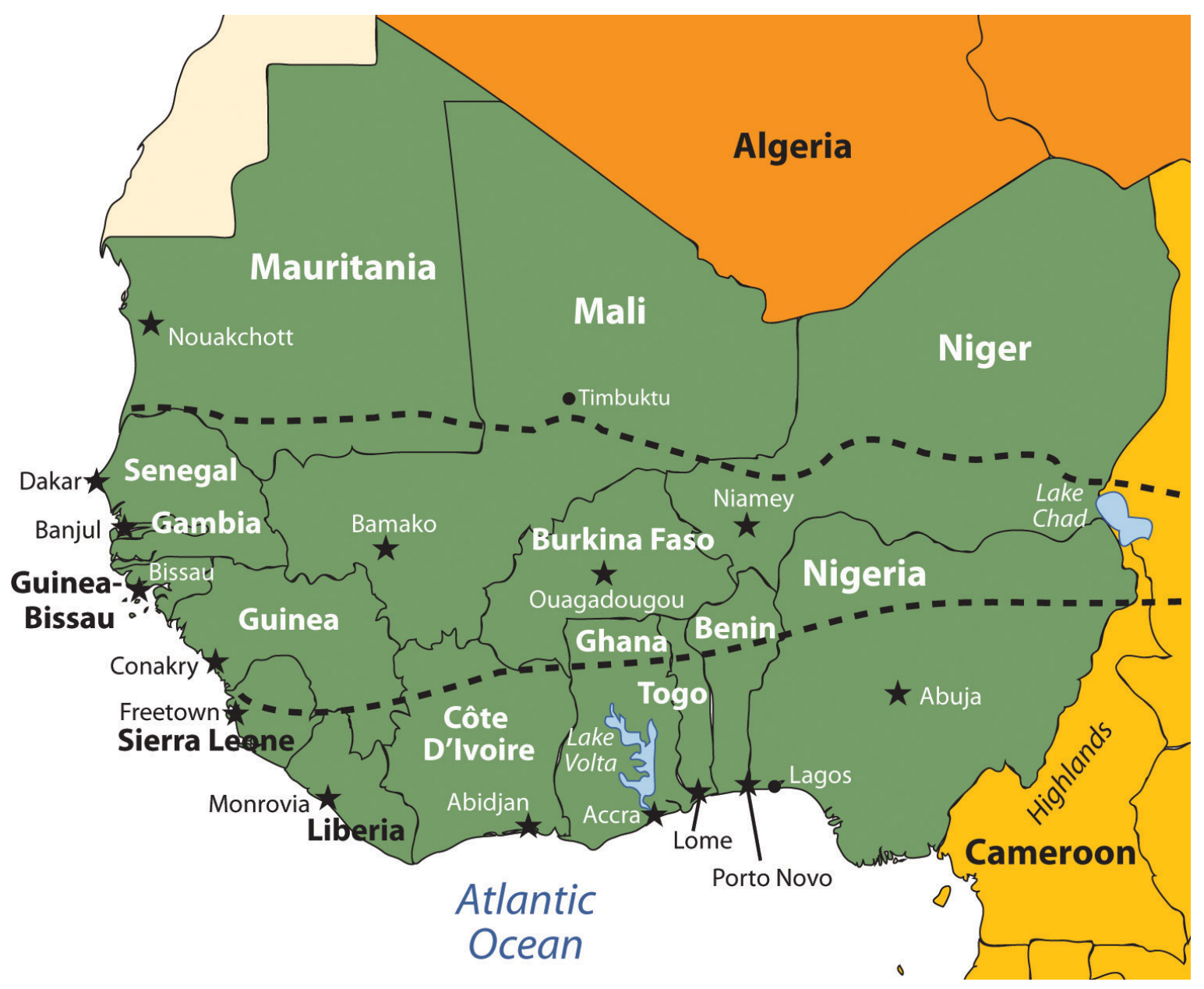

Figure 3. Map of West Africa. 
It has been noted that the majority of West Africans in Africa are not aware that they have hypertension. This has been attributed to the lack of physically identifiable symptoms. Different studies have demonstrated that the level of awareness ranges from $22 \%$ to $54 \%$ across West Africa (Agyemang, Bruijnzeels, \&Owosu-Dabo, 2006; Bosu, 2010).

Barriers to seeking care include the fact that some West Africans do not understand the concept of chronic illness and lifelong maintenance therapy. Instead many see hypertension as an acute illness that is curable (Bosu, 2010). Researchers have also found that in West Africa the high cost of medications has a negative effect on compliance to treatment regimen. There is no functioning system of primary healthcare in West Africa, which makes it difficult for patients to obtain a reliable free or inexpensive medication (Bosu, 2010; Perkovic, Huxley, Wu, Prabhakaran, \& MacMahon, 2007). Across West Africa, patients choose to use herbal treatments which are readily available and relatively inexpensive (Bosu, 2010).

There are no national treatment guidelines for the management of hypertension in any of the nations of West Africa. Healthcare providers lack the basic practical information required to provide appropriate care to people with hypertension. This may account for inadequate counseling of patients and failure of providers to stress lifestyle interventions when developing plans for the prevention and/or management of hypertension (Bosu, 2010; Perkovic, Huxley, Wu, Prabhakaran, \& MacMahon, 2007). Many residents in West African are unable to access the health care system. In turn, the healthcare system is not able to identify and subsequently provide care to people with 
high blood pressure (Agyemang, Bruijnzeels, \&Owosu-Dabo, 2006; Perkovic, et al., 2007). This gap can be attributed to the lack of a primary healthcare system in West Africa, the cost of access to healthcare, and the relatively easy availability of alternative treatments

\section{Barriers to Blood Pressure Control in Blacks/African Americans}

Although the inability to achieve optimum blood pressure control is a pervasive problem in the general populace, lack of control is more prevalent among blacks in the U.S. In the NHANES report 2010, it was noted that awareness of the condition of hypertension and available treatment options was in fact greater among blacks in comparison to whites and Hispanics. However, the proportion of those patients with hypertension who were treated and had achieved control was higher among whites (Egan et al., 2010). The barriers to high blood pressure prevention and management among U.S. blacks or African Americans falls into four areas: the health system, the community, the family, and the individual (Wexier, Elton, Piester, \& Feldman, 2009). The major barrier identified by researchers is a lack of trust in the healthcare system (Elder et al., 2012; Fongwa et al., 2008; Wexier, et al., 2009). The issue of African Americans' mistrust in the healthcare system dates back to the 1932 Tuskegee Syphilis Study during which black males were left untreated even after the discovery and availability of penicillin (Gamble, 1997). Some members of a subsequent study reported feeling like "guinea pigs" for the health care system (Wexier, et al., 2009). This lack of trust in the healthcare system affects many aspects of care. A survey to determine the impact of trust on medication adherence and hypertension control in Southern African 
American men, found that the patients who reported higher levels of trust in the healthcare system were more likely to report better medication adherence and better blood pressure control (Elder et al., 2012). The result of a similar study with African American women revealed the same findings (Fongwa et al., 2008). Other barriers have been described as inaccessible health education programs regarding high blood pressure prevention and control, inadequate financial resources, inconveniently located healthcare facilities, and long wait times within those facilities (Hildreth \& Saunders, 1991; Wexier, et al., 2009).

Wexier, et al (2009) reported that as a community, African Americans tend to have a fatalistic response to hypertension. Some participants in a focus group aimed at learning African Americans perspectives on high blood pressure control, referred to high blood pressure as a "generational thing" (p.599), implying that hypertension is an inevitable disease based on family lineage. African Americans, who believed that hypertension was inevitable, subsequently also questioned the validity of following a special diet, participating in a program of exercise, and enduring the side effects of medications in order to help prevent or control hypertension. Other community level barriers identified by researchers are psychosocial and environmental stressors which include: underemployment, unemployment, perceived racism, lack of social support, higher rates of poverty, and crowded and substandard living environments (Barnes, Schneider, Alexander, \& Staggers, 1997; Hildreth \& Saunders, 1991). Some African Americans view hypertension as merely a genetic disease which one gets by belonging to a particular family and nothing one does can change it. In addition, the practice eating of 
traditional dishes which are generally laden with fats and salt was identified as a family level barrier to high blood pressure control (Wexier, et al., 2009).

The barriers to high blood pressure control at the individual level includes: lack of understanding of the etiology of hypertension, lack of physical activity, obesity, lack of insurance and inability to afford medications, consumption of an unhealthy diet, the experience of comorbid conditions, stress, the side effects of medications not adhering to medication regimen, and lack of willingness to change their lifestyle (Anthony,Valinsky, Inbar, Gabriel, \& Varda, 2012; Wexier, et al 2009). In a focus group developed to determine the perception of hypertension treatment among patients with or without diabetes, a participant was noted to say “.... [I] am not willing to invest everything in health; hypertension will not disrupt my lifestyle" (Anthony et al 2012,p.4). Participants in the same focus group also admitted to self-adjusting medication dosages to fit their bodies based on their perceived stress levels or discontinuing the use of the medication altogether, further illustrating individualized patient barriers to optimal high blood pressure treatment.

\section{Gaps in the Literature}

Database searches failed to produce any literature assessing barriers to hypertension control specifically among West African Immigrants in the U.S. A likely explanation for this is that demographically, all blacks in the U.S are often identified as one population - black non-Hispanic or black/African American. As noted earlier, the incidence of hypertension among West African immigrants increases with urbanization 
(Agyemang et al., 2006); hence further research is needed to explore this phenomenon in the more urbanized areas of the U.S. with immigrants from West Africa. 


\section{Method}

\section{Purpose}

The purpose of this study was to discover, from interviews, the barriers to the prevention and control of high blood pressure among some West African immigrants living in Rhode Island.

\section{Design}

The study employed a semi-structured interview method to elicit a detailed contextual explanation of barriers encountered by the sample when seeking health care assistance related to hypertension. An in-depth interview method was chosen as the qualitative method of choice. An in-depth interview with a small number of respondents enables the researcher to explore respondents' perspectives on a given issue. The participants have the chance to provide as much detail as possible on a subject without the interviewer necessarily interjecting their views into it (Boyce \& Neale, 2006). This data collection method also provides the participants a sense of privacy that may free him or her to speak without fear or intimidation. As a member of the West African community, this researcher understands that West Africans are very private people who prefer not to discuss their health issues in public settings or an open forum. Utilizing the semi-structured in-depth interview design enabled the researcher to objectively listen to the participants' perspectives on the barriers to high blood pressure prevention and control. 


\section{Participants}

The study was of a convenience sample of five West African immigrants. The inclusion criteria required that the individual be a foreign born West African immigrant with a diagnosis of hypertension, an age of eighteen years or older, the ability to consent to be interviewed and willing to have their conversation audio taped. Volunteers were excluded if he/she was unable to communicate in English, unable to consent to be interviewed, or have the conversation audio taped.

\section{Site}

Given a choice of where to conduct the interview, all participants in this study opted to have the interview in their respective homes as this provided them with a sense of security and privacy as they shared their information.

\section{Procedure}

In February 2013, the Human Subject Institutional Review Board (IRB) of Rhode Island College provided an approval of the research proposal. Participant recruitment and interviews occurred over a three-week period, beginning from March $5^{\text {th }}$ to March $28^{\text {th }} 2013$ IRB approved flyers were placed on two informational boards at the African Alliance Center of RI. Participants who responded to the flyers were contacted by phone to affirm their interest in participating in the research and to arrange for a time and convenient location for the interview. On the day of the interview, each participant was made aware of a ten-dollar incentive available to participants in the research. The participants were told that they could keep the ten-dollar incentive even if he/she decided at any time not to continue to participate in the research. The researcher read the consent 
form to each participant. Participants were then given an opportunity to ask questions concerning the research. A verbal consent to be interviewed and audio taped as well as a written informed consent were obtained from each participant.

\section{Measurement}

The interview process involved using an interview schedule comprised of seven open ended questions. Appendix B lists the questions: (a) a short description of current health status (Q1); (b) year and place of first diagnosis of hypertension (Q2); (c) the meaning of hypertension to the individual (Q3); (d) Factors that might have contributed to the presence of hypertension (Q4); (e) Treatment measures employed (Q5); (f) The efficacy of treatment employed (Q6); and (g) Possible barriers to blood pressure management. The interview schedule was developed by the researcher after an extensive literature review and then pilot tested before the research process began. Participants also completed a brief demographic data sheet that had generic identifiers of country of origin, age, year of first migration to the U.S, years of formal education, family status, employment status, and health insurance status (Appendix C). Each interview lasted approximately fifteen to thirty minutes.

\section{Ethical Consideration}

Approval for the study was obtained from the Rhode Island College Institutional Review Board responsible for the protection of human subjects in research. The research had minimal risk related to the privacy of information shared by participants. To ensure privacy, participants' names and date of birth were excluded from the interview, only generic identifiers were used. The signed informed consents, the audio recordings, and 
the transcripts of these recordings are stored in a lock cabinet accessible only to this researcher in accordance with the college IRB requirements. The transcript and audio records will be kept in storage for up to three years after which all data will be destroyed.

\section{Data Analysis}

The researcher utilized descriptive statistics to categorize the demographic information provided by the respondents as shown in Table 3. The audio-recorded interviews were transcribed into written documents by a professional transcribing and coding agency. The researcher reviewed each transcript with the companion audio-tape for accuracy. A few corrections were made to the transcripts before submitting them for preliminary content coding using Nvivo 10 qualitative analysis software. The preliminary content coding identified a broad analytical framework of categories based on answers provided by the participants.

Nvivo 10 is qualitative analysis software that allows for consistent coding schemes and provides the researcher with tools to query and audit the coding processes, thereby producing more robust interpretations of data (Bergin, 2011). The coding process involved systematically reading through each transcribed interview. Nodes were attached to relevant segments of the interview. The nodes were derived by two methods. First, a node was created for each question asked in the interview schedule; for instance, a node termed "meaning of high blood pressure" was created and each response to the question "What do you understand by (the term) "high blood pressure?" was coded at this node. A research query was carried out to identify the most frequently used words in the 
interview process. The words identified were recoded under specific themes that identified the barriers to hypertension control as perceived by each respondent.

Trustworthiness of the analysis was addressed using the following methods. First, the audio taped interview was transcribed by a professional coding and analysis agency. The researcher read through the transcript while listening to the tape to ensure accuracy. Second, the transcribed interviews were each coded independently by the research agency and the researcher using the same software. The researcher then went through the codes with the agency to discuss the meaning of the few instances where conflicting codes were generated.

Soliciting the respondents' personal account of perceived barriers to controlling high blood pressure ensured the credibility of this research. The responses generated were categorized under themes that emerged from respondents' verbiage as it appears in the interview. This removed the researcher's biases from the process. Member checking verified the themes that emerged. Research participants were contacted by phone to verify the findings and clarify description given. Also, the fact that more than one participant mentioned similar themes further ensures the credibility of findings in this research.

The transferability of results in this research was addressed by sharing findings with an expert West African clinician who is familiar with the phenomenon being studied. The transferability of the identified barriers is also supported by the fact that similar results have been obtained by previous research works with African Americans and other ethnic minorities in the U.S. and internationally by researchers in West Africa. 
It is hoped by this researcher that the results of this study will add to the body of knowledge available on barriers to high blood pressure control in West African immigrants living in R.I. Asking all the research participants to confirm the findings of the research. an audit trail of the research process, and reports generated automatically by the Nvivo 10 analytical software help to assure the reliability of these findings for this sample. 


\section{HIGH BLOOD PRESSURE IN WEST AFRICAN IMMIGRANTS IN RI}

\section{Results}

Five volunteers who self-identified as West Africans were interviewed. Three of the participants were women and two participants were male. The mean age of participants was 50 years old, with a range of 30 years to more than 60 years. All participants had at least a twelfth grade education. Three participants had a full time employment with two having an employer-based private health insurance, and one with the state health insurance. One participant was unemployed and had no health insurance and the remaining participant was self-employed with no health insurance. The results of the demographic characteristics of the participants are displayed in Table 3. All but one participant described their current health as "good". All the participants stated that the diagnosis of hypertension was an incidental diagnosis. In regard to the question "what do you understand by hypertension?" the most coded word was "headache and stress", with one referring to hypertension as "something that gives you malaria". The most coded word in reference to contributing factors was also "stress". The dominant code in reference to treatment and management was "medication" "belief" and "diet". Side effects was mentioned once only. Finally, the most coded barrier to hypertension management was "stress". The major barriers identified by participants are displayed in Table 4. 
Table 3

Demographic characteristics of study participants

\begin{tabular}{|c|c|c|}
\hline Demographic Variable & $\mathrm{n}$ & $\%$ \\
\hline \multicolumn{3}{|l|}{ Gender } \\
\hline Male & 2 & 40 \\
\hline Female & 3 & 60 \\
\hline Age Range & 1 & 20 \\
\hline $30-39$ & 1 & 20 \\
\hline $40-49$ & 2 & 40 \\
\hline $50-59$ & 1 & 20 \\
\hline \multicolumn{3}{|l|}{$\geq 60$} \\
\hline & 3 & 60 \\
\hline Country Of Birth & 1 & 20 \\
\hline$\overline{\text { Nigeria }}$ & 1 & 20 \\
\hline Liberia & & \\
\hline \multirow[t]{2}{*}{ Sierre Leone } & 2 & 40 \\
\hline & 3 & 60 \\
\hline \multicolumn{3}{|l|}{ Health Insurance } \\
\hline \multicolumn{3}{|l|}{ No } \\
\hline \multicolumn{3}{|l|}{ Yes } \\
\hline & 3 & 60 \\
\hline Employment & 1 & 20 \\
\hline Full Time & 1 & 20 \\
\hline Self Employed & & \\
\hline Retired & 1 & 20 \\
\hline & 3 & 60 \\
\hline Year of First Migration & 1 & 20 \\
\hline $1991-1999$ & & \\
\hline $2000-2010$ & 1 & 20 \\
\hline$\geq 2010$ & 1 & 20 \\
\hline & 1 & 20 \\
\hline Years of Formal Education & 2 & 40 \\
\hline$\overline{\text { Grade } 1-12}$ & & \\
\hline 2 Year College & & \\
\hline 4 Year College & & \\
\hline Masters & & \\
\hline
\end{tabular}


Table 4

Barriers to high blood pressure control

\begin{tabular}{|c|c|c|}
\hline $\begin{array}{l}\text { Adherence to medication } \\
\text { (n=5) } \\
\text { Participant 1: "I do not } \\
\text { take the medication } \\
\text { continuously because I do } \\
\text { not want to depend on } \\
\text { medication to leave my } \\
\text { life." } \\
\text { “....i observe within myself } \\
\text { that as I take these } \\
\text { medications, I experience a } \\
\text { lack of breathing, } \\
\text { diarrhea..... feel like not } \\
\text { taking them because they } \\
\text { introduce other, additional } \\
\text { sickness to what they are } \\
\text { curing" } \\
\text { Participant 2: "Yes I do } \\
\text { because I was scared } \\
\text { Participant 3: "The barrier } \\
\text { I have is I don't take the } \\
\text { medication" } \\
\text { Participant 4: " No } \\
\text { sometimes I forget to take } \\
\text { it" } \\
\text { Participant 5: "the fact }\end{array}$ & $\begin{array}{l}\text { Diet ( } \mathrm{n}=3 \text { ) } \\
\text { Participant 2: "The barrier that I feel, } \\
\text { at times I eat them, but not so often. It } \\
\text { may be part of it, but physically I had a } \\
\text { stressful life." "The only thing is when } \\
\text { you talk about diets, you know there's } \\
\text { some food you would like to eat and } \\
\text { because of your health you won't be } \\
\text { able to eat it." } \\
\text { Participant 3: "Yeah, so things like that. } \\
\text { I know that diet-eating much oil.... } \\
\text { Eating those things that can increase } \\
\text { fat in your body, when you eat so much } \\
\text { of that, it can cause you sickness." } \\
\text { Participant 5: "I'm an extrovert. I like } \\
\text { to do things when I want to do. I feel } \\
\text { like if I want to have a drink of soda, I } \\
\text { should drink soda....... The mere fact } \\
\text { that I have to consider the components } \\
\text { of whatever I put in my mouth is...it's } \\
\text { inhibitive" }\end{array}$ & $\begin{array}{l}\text { Stress ( } \mathbf{n = 5} \text { ) } \\
\text { Participant 1: "When I ask the } \\
\text { medical person the cause of all } \\
\text { the blood pressure, she said it } \\
\text { was as a result of stress..........it } \\
\text { was my own nephew who was } \\
\text { sick..........then when I thought } \\
\text { of the things I have suffered as } \\
\text { a result of that boy's situation, } \\
\text { it got into my } \\
\text { health...........there were things } \\
\text { that caused me to rather } \\
\text { develop high blood pressure.” } \\
\text { Participant 2: "I was doing } 7 \mathrm{~A} \\
\text { to 3P, 3P to 11P every day. I'd } \\
\text { do like } 80 \text { hours a week. I was } \\
\text { not used to that type of } \\
\text { stressful life back home. I } \\
\text { think I overworked my heart. } \\
\text { Participant 3: "I worked so } \\
\text { hard every day, I did not rest } \\
\text { myself, because I have to bring } \\
\text { my family over here to join } \\
\text { me” } \\
\text { Participant 4: "one of the } \\
\text { most important one was....... } \\
\text { It's one, worriness" }\end{array}$ \\
\hline
\end{tabular}




\begin{tabular}{|c|c|c|}
\hline $\begin{array}{l}\text { medication every day it's } \\
\text { enough headache for me" }\end{array}$ & & $\begin{array}{l}\text { Participant 5: "of course, to } \\
\text { some level, yes. Stress is } \\
\text { something you have to deal } \\
\text { with in life" }\end{array}$ \\
\hline $\begin{array}{l}\text { Belief System (n=3) } \\
\text { Participant 1: "Yeah, to } \\
\text { live my life, yes I want to } \\
\text { depend much on what my } \\
\text { faith in God says." } \\
\text { Participant 4: "Yeah, } \\
\text { sometimes, you know, I } \\
\text { feel all right. I say I'm all } \\
\text { right. Sometimes I believe, } \\
\text { like ..... Sometimes I just } \\
\text { believe by the grace of God } \\
\text { I am fine. Then I just } \\
\text { go........" } \\
\text { Participant 5: "Yes I'm a } \\
\text { Christian. There are many } \\
\text { times I feel like fasting, and } \\
\text { praying and for the mere } \\
\text { fact that I have to take my } \\
\text { medication, I have to } \\
\text { rationalize taking my } \\
\text { medication or to fast }\end{array}$ & $\begin{array}{l}\text { Life Style Modification ( } \mathrm{n}=4 \text { ) } \\
\text { Participant 2: Concerning the exercise, } \\
\text { I didn't have time to go for exercise. } \\
\text { There was a time I registered in the } \\
\text { gym for one year; I went once because } \\
\text { of the work and school I was going. I } \\
\text { had no time to go to gym; by the time } \\
\text { I'm home I'm already tired." } \\
\text { Participant 3: No I really wouldn't } \\
\text { exercise." } \\
\text { Participant 4: Yes I am doing that. It's } \\
\text { tough, it's not easy, but [I]am trying. } \\
\text { Participant 5: I do exercise when I have } \\
\text {.... as an African, exercise is the last } \\
\text { thing that would come to my mind. I } \\
\text { don't believe in it. Put it this way, I } \\
\text { don't have time for it." }\end{array}$ & \\
\hline
\end{tabular}




\section{Conclusion and Implication for Advanced Nursing Practice}

\section{Summary}

Hypertension is an emerging crisis in urbanized West African population. West African immigrants account for one out of every three African immigrants in the U.S. (Immigration Policy, 2012). As such it becomes necessary to understand the factors that contribute to uncontrolled high blood pressure in this aggregate. This pilot study sought to understand from the patient's perspective, the barriers to high blood pressure prevention and control among West Africans living in RI.

Stress: The most commonly discussed barrier to care as identified by participants was "stress". Participants in the research attributed their inability to adequately manage their hypertensive disease to multiple stressors such as a loss in socioeconomic status, adaptation of new employment skills and loss of social support system as reflected in the following quotations:

"I was doing $7 A$ to $3 P, 3 P$ to $11 P$ every day. I'd do like 80hours a week. I was not used to that type of stressful life back home. I think I overworked my heart" "I worked so hard every day; I did not rest myself, because I have to bring my family over here to join me."

This statement is consistent with previous findings of a patient's perceptions of the barriers to high blood pressure management with African Americans in the U.S, and West Africans in Africa. Kuffman et al (1996) noted that the forces driving the increasing prevalence of hypertension in West Africa were associated to lifestyle changes 
resulting from urbanization. They utilized a population-based survey of three Nigerian cohorts (1) rural men and women represented by subsistence agricultural farmers, (2) trade and crafts men representing urban poor and (3) railway workers representing urban wage earners. The results of their study showed an increasing gradient of hypertension from the rural farmers to the urban wage earners.

Kuffman et al, (1996), concluded that urbanization brought with it an increase in stress and a decline of the traditional social support systems and changes in lifestyle and behavior, which separately or together may have contributed to the higher blood pressures in the urban wage earners.

Dietary intake: When speaking of their diets, participants in this study made inferences to diets "saddled with spices and oil" but did not directly identified "salt" as the offending spice. Participants also showed a lack of knowledge about the dietary approach to stop hypertension (DASH-diet) recommended by the JNC VII commission. One participant acknowledged that she has never been told by her primary care physician to reduce the salt content in her diet. This is particularly concerning as research shows that one of the primary physiological mechanisms that causes high levels of high blood pressure in people of black ancestry is the inability of the kidney to excrete sodium (Kaplan, 1998). In the follow up to the Trials of Hypertension Prevention study Cook et al (2007) demonstrated a twenty five percent reduction in cardiovascular related mortality in a low sodium intervention group.

Every participant in this study stated that it was difficult to follow a particular diet as expressed in this quote 
"I'm an extrovert. I like to do things when I want to do. I feel like if I want to have a drink of soda, I should drink soda...... The mere fact that I have to consider the components of whatever I put in my mouth is ...it's inhibitive".

Medication Use: Majority of the participants in this study stated that they adhere to their prescribed medication regimen. Reasons given for adherence were "fear of death, to "medication works for me". Participants stated that they found it easier to adhere to a daily medication regimen than to adopt lifestyle changes like diet, and exercise. Two participants however reported that sometimes they did not take medication. One participant reported she sometimes forgets to take the medication. However, on further probing, the participant admitted to not adhering because “.... sometimes, you know, I feel all right. I say I'm all right. Sometimes I believe, like .... Sometimes I just believe by the grace of God I am fine. Then I just go...." The other participant reported that the side effects of the medication prompted him to sometimes stop or self-adjust the dosages of his medications. These comments supports previous research findings that noted that patients' ability to adhere to a treatment regimen was influenced by their perception regarding the dangers of hypertension and the necessity of treatment based on their personal experiences and beliefs (Anthony et al, 2012).

Alternative remedies: All but one participant denied the use of alternate remedies to manage hypertension. If accurate this is contrary to the findings of other researchers that suggest that some patients do not adhere to western medication and rather chose to use traditional remedies (Brown \& Segal, 1996). 
Prescribed medications: Although participants reported using medications to manage their illness, four out of five participants reported taking ace inhibitors and beta blockers as the mainstay of treatment. This supports inferences that some health care providers are either not aware of the treatment recommendations concerning high blood pressure in ethnic populations or chooses not to adhere to the evidenced-based recommendations (Cook et al, 2006; Ogedegbe, 2008)

Exercise: The participants in this study expressed varying views concerning the concept of exercise as a health promotion intervention. One participant expressed unwillingness to exercise as follows "I do exercise when I have [time].... as an African, exercise is the last thing that would come to my mind. I don't believe in it. Put it this way, I don 't have time for it." Participants' comments indicated that they appeared to view exercise as an additional stressor to their lives.

\section{Conclusion}

In summary most West Africans who migrate to the U.S come in here to seek "greener pastures". However, when West Africans arrive in the U.S they are faced with an abrupt change in social and economic status. They loose their identity as members of a majority group and assume a minority status. In addition, many stated that they are working two or three jobs in order to survive here and also support their relatives in their native countries. The stress incurred from this amount of work, improper dietary habits, and an unwillingness or inability to adopt an exercise regime, places them at a higher risk of experiencing the complications of heart disease and stroke as a result of poorly controlled high blood pressure. 


\section{Limitations}

The limitation of this study lies in the self-selection process of the convenience sample and the limited sample size. The use of a small convenient sample size may not necessarily reflect the views of all West Africans in R.I, and limits the generalizability of this research. However, this study as a pilot study identifies several self- reported barriers to high blood pressure control among West African immigrants living in R.I. that the researcher believes can serve as a preliminary data from which healthcare providers can develop interview questions in order to learn the individual interventions required of West African immigrants with the diagnosis of hypertension.

\section{Recommendations and Implications for Advance Practice Nursing (APRN)}

As noted by previous researchers, high blood pressure is a complicated illness requiring multiple treatment approaches delivered in an ongoing process. This researcher recommends that providers, who encounter West Africans in their practice, should make every effort to follow the treatment guidelines recommended by the International Society of Hypertension in Blacks closely, while also individualizing the plan of therapy for each patient.

It is imperative that each advanced practice registered nurses (APRN) fulfill their role as patient educators/counselors. In discussing lifestyle modifications with patients, an APRN should avoid the use of generic terms like "spices", and "diet". The use of salt and the role of sodium in high blood pressure should be emphasized and the DASH diet should be discussed as an option with patients. Patients should be provided a copy of the DASH diet as a visual that will enhance their understanding and compliance. When 
needed an APRN should refer patients to a nutritionist who is familiar with the diets followed by West Africans and provide the recommended nutritional management information. Each APRN should reinforce the importance of physical activity in high blood pressure management. Patients should be told that getting involved in an exercise activity is not synonymous with going to the gym. Patients should be taught that simple changes like taking the steps rather than the elevator is beneficial to their health.

Our practice as an APRN demands that we view the patient as a whole entity and not as a person with a disease. Hence it is imperative that an APRN seeking to provide culturally based care to West Africans adopt a psychosocial paradigm of high blood pressure. This will involve assessing the patient's stressors, and working with the patient to adopt a stress reduction strategy. This pilot study suggest that the ability to manage the daily stressors faced by West Africans in adapting to their new environment, may enhance adherence to treatment and ultimately enhance blood pressure control and mitigate future morbidity and mortality. 


\section{References}

African Alliance of Rhode Island. (2011). Report of Findings of Focus Groups with African Immigrants. Retrieved from The Rhode Island Department of Health Web site: www.health.ri.gov.

Agyemang, C. (2006). Rural and Urban differences in blood pressure and hypertension in Ghana, West Africa. Journal of the Royal Institute of Public Health, 120, $523-$ 533.

Agyemang, C., Bruijnzeels, M. A., \& Owusu-Dabo, E. (2006). Factors associated with hypertension awareness, treatment, and control in Ghana. Journal of Human Hypertension, 20, 67-71.

Alligood, R. M., \& Tomey, M. A. (2010). Nursing Theorists and Their Work (7th ed.). Maryland Heights, Missouri: Mosby Elservier.

Anderson, N. B., \& Myers, H. F. (1989). Hypertension in blacks: psychosocial and biological perspectives. Journal of Hypertension, 7, 161 - 172.

Anthony, H., Valinsky, L., Inbar, Z., Gabriel, C., \& Varda, S. (2012). Perceptions of hypertension treatment among patients with and without diabetes. Biomed Central Family Practice, 13(24).

Atlas. (n.d.). Atlas West Africa. Retrieved from Atlas Web site: www.atlaswestafrica.org

Barnes, V., Schneider, R., Alexander, C., \& Staggers, F. (1997). Stress, Stress Reduction, and Hypertension in African Americans: An Updated Review. Journal of the National Medical Association, 89(7), 464 - 476. 
Bergin, M. (2011). NVivo 8 and Consistency in Data Analysis; Reflecting on the use of a Qualitative Data Analysis Program. Nurse Researcher, 18(3), 6-12.

Berlowitz, D. R., Ash, A. S., Hickey, E. C., Friedman, R. H., Glickman, M., Kader, B., \& Moskowitz, M. A. (1998). Inadequate Management of Blood Pressure in a Hypertensive Population. The New England Journal of Medicine, 339(27), 19571963.

Berry, J. W. (1997). Immigration, acculturation, and adaptation. Applied Psychology: an International Review, 46(1), 5 - 68.

Bolyai, S. S., Bova, C., \& Harper, D. (2005). Developing and refining interventions in persons with health disparities: The use of Qualitative Description. Nursing Outlook, 53, 127-133.

Bosu, W. K. (2010). Epidemic of hypertension in Ghana: A systematic review. Biomed Central, 10, 1-14.

Boyce, C. (2006). Conducting In-Depth Interviews: A Guide for Designing and Conducting In-Depth Interviews for Evaluation Input. Watertown, MA: Pathfinder International.

Brown, C., \& Segal, R. (1996). The effects of health and treatment perceptions on the use of prescribed medicationand home remedies among African Americans and White American hypertensives. Social Science \& Medicine, 43, 903 - 917.

Buene, E., Haafkens, J. A., Schuster, J. S., \& Bindels, P. (2006). 'Under Pressure': How Ghanaian, African-Surinamese and Dutch patients explain hypertension. Journal of Human Hypertension, 20, 946-955. 
Center for Disease Control, \& Prevention. (2011). Vital signs: prevalence, treatment, and control of hypertension--United States, 1999-2002 and 2005-2008.MMWR 2011; 60(4): 103-108 Washington, DC: U.S. Government Printing Office.

Center for Disease Control, \& Prevention. (2012). National health and Nutritional Examination Survey: Surveys and data collection systems (2010) (Issue Brief). Retrieved from Center for Disease Control and Prevention Web site: www.cdc.gov/nchs/nhanes.htm

Center for Diseases Control, \& Prevention [CDC]. (2012). National Health and Nutrition Examination Survey: Surveys and data collection systems (2010 data) (Issue Brief). Retrieved from Center for Disease Control Web site: www.cdc.gov/ nchs/nhanes.htm

Chobanian, A.V., Bakris, G.L., Black, H.R., Cushman, W.C., Green, L.A., Izzo, J.L......Wright, J.T (2004). The Seventh Report of the Joint National Committee on Prevention, Detection, Evaluation, and Treatment of High Blood Pressure (Complete Report No 04-5230). Bethesda, MD: NHLBI Health Information Center.

Cook, N. R., Cuttler, J. A., Obarzanek, E., Buring J.E., Rexrode., K.M., Kumanyika., S.K, Appel., L.J., ... Whelton, P. K. (2007). Long term effects of dietary sodium reduction on cardiovascular disease outcomes: observational follow-up of the trials of hypertension prevention (TOHP). British Medical Journal, 1-8. April 23, 2012. doi:10.1136/bmj.39147.604896.55 
Cook, S., Drum, M.L., kirchoff, A.C., Jin, L., Levie, J., Harrison, J.F.....Chin, M.H (2006). Providers' Assessment of Barriers to Effective Management of Hypertension and Hyperlipidemia in Community Health Centers. Journal of Health Care for the Poor and Underserved, 17, 70-85.

Drazner, M. H., Dries, D.L., Peshock, R.M., Cooper, R.S., Klassen, C., Kazi, F..... (2005). Left ventricular Hypertrophy Is More Prevalent in Blacks than Whites in the General Population: The Dallas Heart Study. Hypertension Journal of the American Heart Association, 46, 127-129.

Egan, B. M., Zhao, Y., \& Axon, R. N. (2010). US Trends in Prevalence, Awareness, Treatment, and Control of Hypertension. Journal of American Medical Association, 303, 2043-2050.

Elder, K., Ramamonjiarivelo, Z., Wiltshire, J., Piper, C., Horn, W. S., Gilbert, K. L., Hullett, S., ... Allison, J. (2012). Trust, Medication Adherence, and hypertension control in Southern African American Men. American Journal of Public Health, 102(12), $2242-2245$.

Exner, D. V., Dries, D. L., Domanski, M. J., \& Cohn, J. N. (2001). Lesser Response to angiotensin-converting-enzyme inhibitor therapy in black as compared with white patients with left ventricular dysfunction. New England Journal of Medicine, 344, 1351 - 1357.

Flack, J. M., Sica, D.A., Bakris, G., Brown, A.L., Ferdinand, K.C., Grimm Jr, R.H...Jamerson, K.A. (2010). Management of High Blood Pressure in Blacks: An Update of the International Society on Hypertension in Blacks Consensus 
Statement. Hypertension Journal of the American Heart Association, 56, 780800.

Fongwa, M. N., Evangelista, L. S., Hays, R. D., Martins, S. D., Elashoff, D., Cowan, M. J., \& Morisky, D. E. (2008). Adherence treatment factors in hypertensive African American women. Vascular Health and Risk Management, 4(1), 157 166.

Gamble, V. N. (1997). Under the shadow of Tuskegee: african Americans and health care. American Journal of Public Health, 87, 1773 -1778.

Gibbs, C. R., Beevers, D. G., \& Lip, G. Y. (1999). The Management of Hypertensive Disease in Black Patients. Review, 92, 187-192.

Giles, T. D., Materson, B. J., Cohn, J. N., \& Kostis, J. B. (2009). Definition and Classification of Hypertension: An Update. Journal of Clinical Hypertension, 11, 611-615.

Havranek, E. P. (2008). From Black and White to Shades of Gray: Race and ReninAngiotensin System Blockade. Journal of the American College of Cardiology, 51(19), $1872-1873$.

Heidendriech, P. A., Trogdon, J.G., Khavjou, O.A., Butler, J., Dracup, K.,Ezekowitz, M.D Woo, J. (2011). Forecasting the Future of Cardiovascular Disease in the United States. A Policy Statement From the American Heart Association. Circulation, 123, 933-944.

Hildreth, C., \& Saunders, E. (1991). Hypertension in Blacks: Clinical Overview. Cardiovascular Clinics, 21(3), 85 - 96. 
Hsieh, H. F., \& Shannon, S. E. (2005). Three Approaches to Qualitative Content Analysis. Qualitative Health Research, 15, 1277-1288.

Immigration Policy Center. (2012, June). African Immigrants in America: A Demographic Overview [Fact Sheet]. Available March 15, 2013, from Immigration Policy Center Web site: www.immigrationpolicy.org/sites/default/ files/docs/african_fact_sheet.pdf

Institute of Medicine. (2010). A Population-Based Policy and Systems Change Approach to Prevent and Control Hypertension (Report brief). Retrieved from Institute of Medicine of the National Academies Web site: www.iom.edu.

Kaiser Family Foundation. (2010). State Health Fact. Available from www.statehealthfact.org/profileind.jsp? $\mathrm{rgn}=448 \& \mathrm{cat}=9$

Kang, J. H., Han, H., Kim, K. B., \& Kim, M. T. (2006). Barriers To Care and Control of High Blood Pressure in Korean-American Elderly. Ethnicity \& Disease, 16, $145-151$.

Kaplan, N. M. (1983). Hypertension: Prevalence, Risks, and Effect of Therapy. Annals of Internal Medicine, 98, 705-709.

Kaplan, N. M. (1998). Clinical Hypertension. Philadephia, PA: Lippincott Williams \& Wilkins.

Kaplan, N. M., Bakris, G. L., \& Forwan, J. P. (2011). The Prevalence and Control of Hypertension. Retrieved from UpToDate Web site: www.uptodate.com

Kaufman, J. E., Owoaje, E. E., James, S. A., Rotimi, C. N., \& Cooper, R. S. (1996). Determinants of Hypertension in West Africa: Contributions of Anthropometric 
and Dietary Factors to Urban-Rural and Socioeconomic Gradients. American Journal of Epidemiology, 143, 1203-1216.

Keil, J. E., Sutherland, S. E., Knapp, R. G., \& Tyroler, H. A. (1992). Does equal socioeconomic status in black and white men mean equal risk of mortality? American Journal of Public Health, 82, 1133 - 1136.

Kleinman, A. (1980). Patients and Healers in the Context of Culture. An exploration of the borderland between anthropology, medicine, and psychiatry. Berkeley, Los Angeles: University of California Press.

Lavados, P. M., Hennis, A.J., Fernandes, J.G., Medina, M.T., Legtic, B., Hoppe, A.....Jadue, L. (2007). Stroke Epidemiology, prevention, and management strategies at regional level: Latin America and the Caribbean. Series, 6, 360-372.

Leininger, M. (2002). Culture Care Theory: A major Contribution to Advance Transcultural Nursing Knowledge and Practices. Journal of Transcultural Nursing, 13, 189-192.

Lincoln, Y., \& Guba, E. (1985). Naturalist Inquiry. Beverley Hills, CA: Sage Publications.

McCance K, Huether S., Brashers V, \& Rote N. (2010). Pathophysiology, The Biological Basis for Disease in Adults and Children (6th ed.). Maryland Heights, Missouri: Mosby Elsevier. (Original work published 1990).

Migration Policy Institute. (2011). 2011 American Community Survey and Census Data on the Foreign Born by State [Migration Facts, STATS, and Maps]. Available from www.Migrationinformation.org/datahub/acscensus.cfm\# 
Ogedegbe, G. (2008). Barriers to Optimal Hypertension Control. The Journal of Clinical Hypertension, 10, 644-646.

Oliveria, S. A., Lapuerta, P., McCarthy, B. D., L'Italien, G. J., Berlowitz, D. R., \& Asch, S. M. (2002). Physician-related barriers to the effective management of uncontrolled hypertension. Archives of Internal Medicine, 162(4), 413 - 420.

Opie, L. H., \& Seedat, Y. K. (July 2005). Hypertension in Sub-Saharan African Populations. Circulation, 112, 3562-3568.

Pearlman, D. N., Affleck, P., Everage, N., \& Goldman, D. (2009). The Burden of Heart Disease And Stroke: Rhode Island. Providence, Rhode Island: Rhode Island Department of Health, Division of Community, Family Health and Equity, Heart Disease and Stroke Prevention Program.

Perkovic, V., Huxley, R., Wu, Y., Prabhakaran, D., \& Macmahon, S. (2007). The Burden of Blood-Pressure-Related Disease: A Neglected priority for Global Health. Journal of the American Heart Association, 50, 991-997.

Pickering, T. G., Hall, J.E., Appel, L.J., Falkner, B.E., Graves, J., Hill, M.N.......Roccella E.J (2005). Recommendations for Blood Pressure Measurement in Humans and Experimental Animals: Part 1: Blood Pressure Measurement in Humans: A Statement for Professionals From the Subcommittee of Professional and Public Education of the American Heart Association Council on High Blood Pressure Research. Hypertension Journal of the American Heart Association, 45, 142-161. 
Polit, D. F., \& Beck, C. T. (2006). Essential of Nursing Research. Methods, Apprasial, and Utilization (6th ed.). Philadephia, PA: Lippincott Williams \& Wilkins.

Rahman, M., Douglas, J. G., \& Wright, J. T. (1997). Pathophysiology and treatment implications of hypertension in black population. Endocrinology and Metabolic Clinic on North America, 26, 125- 144.

Wright, J. T., Dunn, J. K., Cutler, J. A., Davis, B. R., Cushman, W. C., Ford, C. E., Habib, G. B. (2005). Outcomes in Hypertensive Black and Nonblack Patients Treated with Chlorthalidone, Amlodipine, and Lisinopril. Journal of the American Medical Association, 293(13), 1595 - 1607.

Rhode Island. Social and Demographic Characteristics. (2011). Retrieved from www.migrationinformation.org/datahub/state.cfm?ID=RI

Richards, L. (1999). Using NVivo in Qualitative Research. Bundoora, Victoria, Australia: Qualitative Solutions and Research.

Roger, VL, Go, AS, Lloyd-James, D., Benjamine, E., Berry, J., Borden, W.,...Turner, M. (2012). Heart Disease and Stroke Statistics-2012 Update. A Report From the American Heart Association. Circulation, 125, e2-e220. http://dx.doi.org/10.1161/CIR.0b013e31823ac046

Rusell, B. E., Gurrola, E., Ndumele, C. D., Landon, B. E., O’Malley, J. A., Keegan, T.,...Hicks, L. S. (2010, February). Perspective of Non-Hispanic Black and Latino Patients in Boston's Urban Community Health Centers on their Experiences with Diabetes and Hypertension. Journal of General Internal Medicine, 25, 504-509. 
Scott, J. M., Spees, C. K., Taylor, C. A., \& Wexler, R. (2010, September 30th ). Racial Differences in Barriers to Blood Pressure Control in a Family Practice Setting. Journal of Primary Care \& Community Health, 1, 200-205.

Seedat, Y. K. (2000, April 25). Hypertension in developing nations in sub-Saharan Africa. Journal of Human Hypertension, 14, 739-747.

Stewart, D. W., \& Shamdasani, P. N. (1990). Focus groups: Theory and practice. London: Sage.

The U.S Preventive Services Task Force. (2007, December). Screening for High Blood Pressure in Adults [Policy Brief]. Retrieved from U.S Preventive Services Task Force: www.uspreventiveservicestaskforce.org

United Nations Statistics Division. (2012). Composition of macro geographical (continental) regions, geographical sub-regions, and selected economic and other groupings. Retrieved fromwww.unstats.un.org

Van der, S., Faal, H., Banya, W. A., Dolin, P., Ceesay, S. M., Waltraven, G. E.,...McAdam, K. P. (1997). Nationwide prevalence study of hypertension and related non-communicable diseases. Tropical Medicine International Health, 2 , 1039-1048.

Wang, Y. R., Alexander, G. C., \& Stafford, R. S. (2007). Outpatient Hypertension Treatment, Treatment Intensification, and Control in Western Europe and the United States. Archieves of Internal Medicine, 167, 141-147. Retrieved from www.archinternmed.com

Weber, R. P. (1985). Basic Content Analysis. Sage University Paper Series on 
Quantitative Applications in the Social Sciences. Series no 07-049. Beverly Hills, California: Sage Publications Inc.

Wexier, R., Elton, T., Pieister, A., \& Feldman, D. (2009, June). Barriers to Blood Pressure Control as Reported by African American Patients. Journal of the National Medical Association, 101(10), 597-603.

World Health Organization. (2012). World Health Statistics 2012 [World Health Staticstical Report]. Retrieved from World Health Organization: www.who.int/gho/publications/world_health_statistics

Wyatt, S. B., Akylbekova, E. L., Wofford, M. R., Coady, S. A., Walker, E. R., Andrew, M. E.,... E.,...Jones, D. W. (2008, February 11). Prevalence, Awareness, Treatment, and Control of Hypertension in the Jackson Heart Study. Hypertension Journal of the American Heart Association, 51, 650-656. http://dx.doi.org/10.1161/HYPERTENSIONAHA.107.100081 


\section{Appendix A}

\section{Dietary Approach to Stop Hypertension}

The DASH Diet Eating Plan

\begin{tabular}{|c|c|c|}
\hline Food Group & Daily Servings & Serving Sizes \\
\hline \multirow[t]{3}{*}{ Grains* } & \multirow[t]{3}{*}{$6-8$} & 1 Slicebread \\
\hline & & $1 \mathrm{OZ}$ dry Cereal \\
\hline & & $1 / 2$ cup cooked rice, pasta or cereal \\
\hline \multirow[t]{3}{*}{ Vegetables } & \multirow[t]{3}{*}{$4-5$} & 1 cup raw leafy vegetable \\
\hline & & $1 / 2$ cup cut-up raw or cooked vegetable \\
\hline & & $1 / 2$ cup vegetable juice \\
\hline \multirow[t]{4}{*}{ Fruits } & \multirow[t]{4}{*}{$4-5$} & 1 medium fruit \\
\hline & & $1 / 4$ cup dried fruit \\
\hline & & $1 / 2$ cup fresh, frozen, or canned fruit \\
\hline & & $1 / 2$ cup fruit juice \\
\hline Fat-free or low & $2-3$ & 1 cup milk or yogurt \\
\hline \multicolumn{2}{|l|}{ Fat Milk and } & $1 \frac{1}{2}$ oz cheese \\
\hline milk products & & \\
\hline
\end{tabular}




\begin{tabular}{|c|c|c|}
\hline $\begin{array}{l}\text { Lean meats, } \\
\text { Poultry, and } \\
\text { fish }\end{array}$ & 6 or less & $\begin{array}{l}1 \mathrm{oz} \text { cooked meats, poultry, or fish. } \\
1 \mathrm{egg}\end{array}$ \\
\hline $\begin{array}{l}\text { Nuts, seeds, } \\
\text { and legumes }\end{array}$ & 4-5 per week & $\begin{array}{l}1 / 3 \text { cup or } 1 \frac{1 / 2}{2} \text { oz nuts } \\
2 \text { Tbsp peanut butter } \\
2 \text { Tbsp or } 1 / 2 \text { oz seeds } \\
1 / 2 \text { cup cooked legumes (dry beans and peas) }\end{array}$ \\
\hline Fats and oils & $2-3$ & $\begin{array}{l}1 \text { tsp soft margarine } \\
1 \text { tsp vegetable oil } \\
\text { 1Tbsp mayonnaise } \\
2 \text { Tbsp salad dressing }\end{array}$ \\
\hline $\begin{array}{l}\text { Sweets and added } \\
\text { Sugars }\end{array}$ & 5 or less per week & $\begin{array}{l}1 \text { Tbsp sugar } \\
1 \text { Tbsp jelly or jam } \\
1 / 2 \text { cup sorbet, gelatin } \\
1 \text { cup lemonade }\end{array}$ \\
\hline
\end{tabular}

* Whole grains are recommended for most grain servings as a good source of fiber and nutrients. Serving sizes of cereals vary between $1 / 2$ cup and $1 \frac{1}{4}$ cups, depending on cereal type. Check the product's Nutrition Facts label

Source: U.S Department of Health and Human Services 


\section{Appendix B}

\section{In-depth Interview Schedule}

1. How will you describe your current health status (Probe current health situation, and lifestyle).

2. How did you know you had hypertension? (Probe year of diagnosis, where was diagnosis made, who made the diagnosis).

3. What do you understand by high blood pressure? (Probe feelings related to diagnosis, acceptance of diagnosis, knowledge of potential associated complications of hypertension).

4. Are there any factors that you believe might have contributed to this illness? (Probe belief system, stress, diet, and genetics).

5. Can you describe to me what you have tried so far in managing your hypertension whether you stuck with it or not? (Probe use of medication, exercise, diet, and alternate therapy).

6. Will you say your blood pressure is under control at the moment? (Probe last blood pressure reading, goal blood pressure desired).

7. What if any, are the barriers you have experienced in managing your blood pressure? (Probe adherence, side effects of treatment, access to healthcare, relationship with healthcare provider, and financial ability to pay for treatment). 


\section{Appendix C}

\section{Demographic Data Questions}

1. What is your country of origin?

2. How old are you

3. When did you first migrate to the U.S.?

4. Can you tell me the number of years of formal education you have?

5. Do you have a spouse or partner leaving with you?

6. Do you have kids?

7. Are you currently employed?

8. Do you have health insurance that covers your hypertension care? If yes can you please tell me if you are covered by your employer, Medicaid, Medicare, state basic health plan, or private insurance? 


\title{
Appendix D
}

\section{CONSENT DOCUMENT}

\author{
Rhode Island College
}

\section{An Exploration into the Barriers in the Prevention and Control of High Blood Pressure in West African Immigrants in Rhode Island}

You are being asked to take part in a study about factors that affect the management and control of high blood pressure among West African immigrants in Rhode Island. You were chosen to be in this study because you are a West African living in Rhode Island with a diagnosis of high blood pressure. Please read this form and ask any question you may have before deciding whether to be in the study.

Ntaobasi Udeh, a graduate nursing student at Rhode Island College, is conducting this study with Peggy Matteson PhD. RN as her faculty advisor.

\section{Background Information}

The purpose of this study is to learn about the barriers that affect the control of high blood pressure among West African Immigrants living in Rhode Island. I am asking you to participant because:

- You are a recent West African immigrant from Nigeria, Ghana, or Liberia.

- You are age 18 or older

- You have been told you have high blood pressure

- You are not pregnant

- You are able to speak, understand, and read English Initial here to indicate that you have read and understand this page 


\section{Procedures}

If you choose to take part in this study:

$\S$ I will ask you questions about the barriers you may have encountered related to receiving care for your high blood pressure (hypertension).

$\S$ The interview will be audio taped.

$\S$ The interview will take no more than 90 minutes.

$\S$ The interview may take place in an office at the African Alliance of Rhode Island's main location at 570 Broad Street in Providence, or at another public location of your choice.

$\S$ If I ask you a question you do not want to answer just tell me and I will skip that question.

$\S$ You will receive a $\$ 10$ gift card for your time. If after you understand the process you choose not to participate, you can still keep the gift card.

\section{Risk of Being in the Study}

The main risk of participating in this study is that sharing personal health information or talking about your health care experiences may remind you of difficult situations you have experienced in the past. If this should happen you may choose to not answer a question and continue the interview or to stop the interview and leave. That will be fine. If you wish to discuss the issues with someone, I will give you a list of resources that you can contact, including the Providence Community Health Centers and the RI Free Clinic. 


\section{Benefits to You}

There are no direct health care benefits to you for taking part in this study.

\section{Voluntary Participation}

It is your choice to take part or not take part in all or a piece of this study. You will not be punished if you choose not to be a part of this study or to not answer some questions. You can withdraw freely from this study at any time without a problem. It will not affect your healthcare.

\section{Confidentiality}

I will not tell anybody that you have talked to me. Your name will not be written down or mentioned on the audio recording, and your name will not be mentioned when I write about the study.

I will keep the records obtained during our interview in a locked file. My supervisor can review the records and will also keep your information confidential. In rare cases the Rhode Island College Institutional Review Board (IRB) may choose to look at the records, but your name and other possible identifiers will not be there. The Rhode Island College IRB is responsible for protecting the interests of research participants like you. All information will be kept flocked up for three years after which all notes and tapes will be destroyed Contacts and Questions

The researcher conducting this study is Ntaobasi Udeh. If after we finish you have any questions about me or the study, you may contact me at ntaobasi@aol.com, 401-6998216 or Dr. Peggy Matteson at pmatteson@ric.edu. 
If you think you are treated unfairly or would like to talk to someone other than the researcher about your rights or safety as a research participant, please contact Dr Christine Marco, Chair of the Rhode Island College Institutional Review Board at IRB@ric.edu or by phone at 401-456-8598, or by writing to Dr Christine Marco, Chair IRB; c/o Department of Psychology, Horace Mann Hall 311; Rhode Island College; 600 Mount Pleasant Avenue; Providence, RI 02908.

You will receive a copy of this form for your records

\section{Statement of Consent}

I have read and I understand this form, and I agree to take part in the study "An Exploration into the Barriers in the Prevention and Control of High Blood Pressure in West African Immigrants in Rhode Island.” I have had the opportunity to ask questions and have had them answered to my satisfaction. I voluntarily agree to participate in this study with the understanding that I may stop answering questions at any time. I will contact the researcher with any future questions that may arise. I am at least 18 years of age. I am at least 18 years of age. I am not giving up any legal rights by signing this form.

I agree do not agree to be audio taped for this study.

Printed Name of Participant

Signature of Participant

Date

Name of Researcher obtaining consent Initial here to indicate that you have read and understand this page 
RIC Institutional Review Board Matteson/Udeh Consent Form Approval \# 1213-41 Version 2/16/2013 Expiration date $2 / 17 / 2014$ 